\title{
O CARÁTER INVESTIGATIVO EM UMA SALA DE AULA APOIADA EM LAKATOS E A SEQUÊNCIA FEDATHI
}

\section{THE INVESTIGATIVE CHARACTER IN A CLASSROOM SUPPORTED IN LAKATOS AND THE FEDATHI SEQUENCE}

\author{
Milínia Stephanie Nogueira Barbosa Felício \\ Secretaria de Educação do Ceará - SEDUC \\ Elaine De Sousa Teodósio² \\ Secretaria de Educação do Ceará - SEDUC \\ Hermínio Borges Neto ${ }^{3}$ \\ Universidade Federal do Ceará
}

\begin{abstract}
Resumo
O aluno que investiga em sala de aula e constrói esforços para o seu aprendizado, desenvolve habilidades inerentes ao conhecimento matemático. Ao tocar o ensino médio, muitos alunos se deparam com grandes dificuldades: a leitura de uma questão, a generalização, a aplicação de uma fórmula. Normalmente, essas dificuldades advêm não apenas de uma base matemática deficiente. A História da Matemática pode ser uma ferramenta útil tanto para o professor, quanto para o aluno. O livro A Lógica do Descobrimento Matemático: Provas e Refutações mostra como uma teoria em crescimento pode se desenvolver em sala de aula, ao debater a definição de poliedros e os questionamentos do campo de validade para a fórmula $\mathrm{V}-\mathrm{A}+\mathrm{F}=2$ (Quantidade de vértices, menos número de quantidade de arestas mais o número de quantidade de faces resulta em dois). O professor que ler e se interessa por História da Matemática, além de ganhar um maior conhecimento para dar suporte ao seu aluno, ao ler o livro de Lakatos, autor da obra mencionada acima, pode entender a dinâmica da sala de aula imaginária apresentada por ele, se questionar e relacionar com a metodologia utilizada em sala de aula. O conteúdo de História da Matemática que vai ser explorado e a metodologia que será utilizada na aula farão papéis bastantes importantes. O professor deve ser criativo e estar preparado a fim de que sua aula seja interessante. Um dos objetivos de Lakatos com a obra é criticar o formalismo, pois para ele este esconde toda a história, a aventura, o período crítico das teorias, prevalecendo as expressões matemáticas. Como abordagem e direcionamento de sala de aula temos como sugestão a Sequência Fedathi, metodologia direcionada para o professor, já que este é quem realmente pode resolver os problemas de ensino.
\end{abstract}

Palavras-chave: Lakatos; Sequência Fedathi; História da Matemática; Sala de Aula.

\footnotetext{
${ }^{1}$ E-mail: millinia@gmail.com

${ }^{2}$ E-mail: elaineteodosio_01@yahoo.com.br

${ }^{3}$ E-mail: herminio@ufc.br
} 


\begin{abstract}
The student who investigates in the classroom and builds efforts for his learning, develops skills inherent in mathematical knowledge. When arriving at high school many students face great difficulties: the reading a question, the generalization, the application of a formula. Usually, these difficulties come not only from a poor mathematical base. The History of Mathematics can be a useful tool for both the teacher and the student. The book Proof and Refutations: The Logic of Mathematical Discovery, shows how a growing theory can evolve in the classroom by discussing the definition of polyhedra and questioning the validity field for the formula $\mathrm{V}-\mathrm{A}+\mathrm{F}=2$ (Quantity of vertices, minus the number of edges, plus number of faces equals in two). The teacher who reads and is interested in History of Mathematics, in addition to gaining greater knowled ge to support his student, while reading the book of Lakatos, author of the work mentioned above, can understand the dynamics of the imaginary classroom presented by him, if he questions and relates to the methodology used in the classroom. The content of History of Mathematics to be explored and the methodology that will be used in the lesson will play quite important roles. The teacher should be creative and be prepared to make the lesson interesting. One of Lakatos's objectives with his work is to criticize formalism, since for him this conceals the whole story, the adventure, the critical period of the theories, prevailing mathematical expressions. For classroom approach and guidance we have as a suggestion the Fedathi Sequence, a methodology directed to the teacher, since this is the one who can really solve the problems of teaching.
\end{abstract}

Keywords: Lakatos; Fedathi Sequence; History of Mathematics; Classroom.

\title{
Introdução
}

Em primeiro lugar devemos nos questionar o tipo de ensino que os alunos estão recebendo hoje nas escolas, se os professores estão explorando a Matemática de forma eficaz, a fim de que seus alunos compreendam os processos e sejam capazes de realizar a manipulação de algoritmos. Para Chevallard et al. (2001), a presença da Matemática na escola é resultado da sua existência na sociedade, portanto deveriam suas práticas estar subordinadas a vida em sociedade. Podemos considerar que sejam dessa sociedade ou de sociedades passadas, visto que a História da Matemática pode justificar diversos elementos de como a Matemática foi desenvolvida ao longo do tempo.

Os resultados da avaliação de 2015 do Programa Internacional de Avaliação de Estudantes (PISA) concluíram que um em cada quatro alunos brasileiros do ensino fundamental, não conseguem utilizar inferência direta e interpretação literal de resultados para resolver problemas. Significa, portanto, que o jovem brasileiro tem dificuldade em interpretações que são imediatas e na leitura da própria escrita. 
Portanto, o desenvolvimento do raciocínio lógico e do raciocínio lógico matemático, ferramentas indispensáveis a essa habilidade, ficam fragilizadas, gerando nestes alunos, maior dificuldade em generalizar afirmações corretamente. O contato com a História da Matemática pode ajudar estes jovens a trabalhar a interpretação e a própria escrita. Além do mais, o jovem muitas vezes não tem motivação. Segundo Ambrósio (2015), a matemática que se ensina hoje nas escolas não é contextualizada, não é tratada como fato histórico, portanto, é considerada estática, o que em muitos casos não gera interesse para o aluno. O professor deve estimular o lado investigativo, crítico do aluno para que ele possa desenvolver habilidades fundamentais para investigar em sala de aula.

Lakatos, seguidor da Teoria do conhecimento cientifico de Popper cria em seu livro A Lógica do Descobrimento Matemático, uma sala imaginária a qual por meio de uma crônica relata o crescimento de uma Teoria Matemática. Nossos alunos estão acostumados a pegar um conteúdo pronto, o que gera a falsa ideia que a Matemática está inacabada, que tudo já foi feito e nada mais se tem a descobrir.

A Sequência Fedathi (SF), que se faz presente no trabalho, é uma metodologia iniciada pelo professor Hermínio Borges Neto durante o seu pós-doutorado na França e visa, primordialmente, a maior participação do aluno na construção de seu conhecimento, podendo ser utilizada em várias disciplinas, sejam elas da área de Humanas, Ciências da Natureza, Linguagens e Códigos ou Matemática. É uma metodologia voltada para o professor.

\section{A sala de aula imaginária do livro A Lógica do Descobrimento Matemático}

Lakatos usa em seu livro A Lógica do Descobrimento Matemático: Provas e Refutações, uma crônica de como se desenvolveu o crescimento da teoria de $\mathrm{V}-\mathrm{A}+\mathrm{F}=2$, enquanto em notas de rodapé conta a real história.

De fato, a sala de aula de Lakatos é formada por alunos de nível avançado, assim como cita em seu livro e para eles tudo era muito encantador, mas nem sempre é assim. Alguns alunos têm mais dificuldades e precisam de um maior esforço por parte do professor, a fim de responderem seus questionamentos sobre a serventia da matemática. D’Ambrósio (2012) cita como experiência matemática por exemplo a respeito desse teorema: 
Ou o famosíssimo teorema dizendo que nos poliedros convexos o número de vértices menos o número de arestas mais o número de faces é sempre igual a 2 , isto é $\mathrm{V}-\mathrm{A}+\mathrm{F}=2$. Claro, um ou outro aluno vai encontrar nesses exemplos seu interesse e, quem sabe mesmo sua vocação de matemático. Mas para a enorme maioria, isso não faz qualquer sentido, é desinteressante e obviamente inútil. Temos tido experiência de muitos jovens, principalmente os de menos idade, dos primeiros anos do ensino fundamental II, que gostam de brincar com essa fórmula. No primeiro caso, usando uma calculadora. No segundo, contando os números de vértices, de arestas e de faces em sólidos e verificando a fórmula. Matemática é isso. (p.91.)

O professor deve tornar o conhecimento mais acessível para o aluno. Lakatos fez com que seus alunos chegassem a essa fórmula, partindo inicialmente de um estudo de polígonos para posteriormente estudar os poliedros. Uma fórmula, apenas lançada para aplicações, não será absorvida por todos positivamente, ela precisa ser desenvolvida.

$\mathrm{O}$ aluno precisa entender que o problema original era mais simples e foi crescendo, partindo da ideia de polígonos onde, $\mathrm{A}=\mathrm{V}$, arestas igual ao número de vértices. Sabe-se que esta fórmula é um problema de Topologia, assunto que nossos alunos do ensino médio não irão entender, mas o professor deve saber até que ponto pode explorar, para que seus alunos entendam que a Matemática surge de dúvidas, de crescimentos de teorias. Lakatos fez com o que os alunos de sua sala imaginária seguissem os passos que os matemáticos fizeram na época. Ao fazer isso, o conteúdo torna-se mais significativo e pode haver uma melhor absorção.

Para Lakatos (1978) seu livro era uma crítica ao formalismo pois considera que este nega o período criativo e críticos das teorias matemáticas. Davis e Hersh (1995) explicam o formalismo como aquele que não se preocupa com os significados das expressões. A História nesse caso se apaga.

\section{A sequência Fedathi como suporte}

Ao utilizar a SF, o professor incentiva o aluno a participar da construção do conhecimento vigente pelos educandos. De acordo com Demo (2012, p. 30 apud Baraldi, 1994; Lajonquière, 1993), “Aprender deve ser um processo lúdico, o que é facilmente visível na criança. Mas, como implica esforço reconstrutivo, também dói, precisamente porque leva a um processo de superações e inovações". É evidente que os professores e alunos estão acostumados com métodos tradicionais de ensino e toda mudança exige esforço. O aluno está acostumado a ter respostas prontas da maioria dos professores de matemática. A história da Matemática, e uma metodologia que faça com que o aluno se 
esforce para chegar as suas próprias conclusões, pode gerar mais ansiedade de ambos os participantes: professor e aluno, mas deve ser colocada o quanto antes em prática. A Sequência Fedathi se divide em quatro fases: Tomada de posição, Maturação, Solução e Prova.

Tomada de posição:

Nessa fase o professor deve escolher um meio de iniciar o conteúdo a ser aprendido, um problema, uma proposição, um texto de História da Matemática, algo que gere no aluno curiosidade. Nesse momento, o professor deve contextualizar o conteúdo. Para que o professor inicie sua aula deve elaborar o plateau, que é a sondagem, o ponto inicial em que os alunos se encontram. Para Borges Neto et al. (2013) antes de apresentar o problema o docente deve fazer um diagnóstico para saber em que nível estão seus alunos e que conhecimentos prévios ele deve ter a fim de ter um bom andamento em sala de aula. Além do mais, a tomada de posição garante a integração do aluno com os elementos necessários para formular questionamentos e exposições durante outras fases da sequência. Esta etapa deve ser elaborada com muito cuidado pois será importante para a motivação do aluno.

Para Lorenzato (2006), é preciso considerar os pré-requisitos cognitivos matemáticos referentes ao assunto que será ministrado a fim de proporcionar que o aluno acompanhe a aula. Para Mendes (2009) é imprescindível que o professor seja ousado e criativo, pois á assim que poderá criar, em sala de aula, um ambiente investigativo que favoreça ao desenvolvimento da imaginação e da criatividade matemática dos estudantes.

\section{Maturação:}

É durante a maturação que o aluno vai refletir sobre o que foi exposto na tomada de posição, seja em grupo, ou individualmente.

\footnotetext{
A partir desse momento, o professor deve dar a possibilidade de interação multilateral, em que ele vai se juntar ao grupo para refletir e problematizar a situação proposta. Esse é o momento em que devem começar os questionamentos. Após a interpretação do problema, os alunos irão pensar as formas de abordar, desenvolver, e finalmente, resolver o problema. Na fase da maturação, o docente deve utilizar perguntas motivadoras que incentivem a criatividade do educando e perguntas esclarecedoras com o objetivo de ajudar o aluno a estabelecer compreensões e relações entre o problema e o caminho para chegar a solução. (DE SOUSA; BORGES NETO, 2003, p.3)
} 
O professor pode levar seus alunos a descobrimento o desenrolar do 'problema' por meio de perguntas, questionando, sem responder todas as dúvidas dos alunos, fazendo-se ausente quando necessário, sempre orientando, para que o aluno siga os passos de um matemático, sem suprimir a criatividade do aluno.

O professor deve agir como um bom professor e não um professor bom. Para Menezes (2016), o professor bom dá uma boa aula, esclarece dúvidas, mas não deixa que o aluno por si só construa a matemática. O professor faz todo o processo sem que o aluno tenha espaço para investigação. Já o bom professor procura levar o aluno a seguir os passos de um matemático.

Fontenele (2018), afirma que na sua gênese, a Sequência Fedathi foi construída para Matemática, mas hoje atua em outras áreas, podendo então o professor de História, fazer com que os alunos percorram os passos de um Historiador, ou os passos de um Biólogo, durante uma aula de Biologia.

\section{Solução:}

Nessa fase os alunos irão apresentar as suas conclusões sobre o problema para a turma. Nesse momento, o docente irá analisar as possíveis soluções juntamente com os alunos, usando a pergunta como fator catalisador e incentivando o aluno a analisar os pontos fracos de suas soluções, não esquecendo de valorizar suas respostas, mesmo se estiverem erradas. Deve-se valorizar o erro e fazer com que o aluno entenda o motivo pelo qual não chegou ao resultado correto. De acordo com Menezes (2018), o estudante adquire autonomia e percebe a importância do caminho que percorreu para sua aprendizagem. Portanto, sentirá que faz parte do processo e se sentirá responsável pelo conhecimento aprendido.

\section{Prova:}

Nessa fase, o professor irá formalizar o conteúdo, chegar a uma conclusão, que pode ser aproveitada durante a Solução de um grupo que chegou ou que se aproximou mais de um resultado. A ideia é que os alunos pensem bastante antes de terem fórmulas e conteúdos prontos, apenas para que apliquem as formas, sem que entendam de fato, para que servem ou como se desenvolvem os raciocínios. Para Polya (2006):

O estudante deve adquirir tanta experiência pelo trabalho independente quanto lhe for possível. Mas se ele for deixado sozinho, sem ajuda ou com auxílio insuficiente, é possível que não experimente qualquer progresso. Se o 
professor ajudar demais, nada restará para o aluno fazer. O professor deve auxiliar, nem demais nem de menos, mas de tal modo que ao estudante caiba uma parcela razoável de trabalho. (p.1.)

De fato, o aluno deverá ser protagonista do seu aprendizado, com o auxílio do professor. Deve ficar evidente também que para reconstruir a Matemática não se precisa ir a origem de tudo, mas trabalhar a essência, para que o aluno consiga dar significado para os conteúdos.

\section{Considerações finais}

Assim como Demo (2012) comenta, na escola tudo vale a pena se o aluno aprende bem, assim com nada vale se o aluno não aprende. A aprendizagem do aluno deve ser o foco do professor e não apenas a mera aula expositiva com excesso de teorias e exercícios. A História da Matemática pode ser uma ferramenta importante para o professor, quando aplica um conteúdo relacionado a cultura, a história contextualizada no tempo atual ou no tempo passado pois dá significado ao aluno, além do mais, o seu estudo pode gerar uma própria reflexão de sua metodologia, como é o caso do livro abordado no trabalho, onde o professor da crônica faz com que seus alunos desenvolvam um conteúdo.

O professor procura entender também se ele não estar sendo tão tradicional ou formalista, esquecendo a riqueza da História Matemática ou o próprio crescimento de uma teoria. O professor que é criativo e tem interesse realmente com o tempo de aprendizado do aluno, e não apenas com a carga horária de sua aula pode investir na História da Matemática e novas metodologias a fim de tornar seu ensino mais produtivo, reflexivo e contagiante, para que o aluno não acredite que a matemática é exclusivamente de cunha escolar, que ela possa ultrapassar as paredes de sala de aula e que o aluno sintase responsável também pela matemática ensinada na aula, que não espere que seu aprendizado seja de compromisso único do professor.

\section{Referências}

BORGES NETO, A. (Org.). Sequência Fedathi no Ensino de Matemática. Curitiba: CRV, 2017.

et al. A Sequência de Fedathi como Proposta Metodológica no Ensinoaprendizagem de Matemática e sua Aplicação no Ensino de Retas Paralelas. São Luiz/MA: XV Encontro de Pesquisa Educacional do Norte e Nordeste 
$2017 \mathrm{a}$.

et al. Sequencia Fedathi no ensino de Matemática. V. 1. Curitiba: CRV, . et al. Sequencia Fedathi: além das ciências duras. V. 2. Curitiba: CRV, $2017 b$. . et al. Sequencia Fedathi: fundamentos. V. 3. Curitiba: CRV, 2018

SANTANA, J. R. Fundamentos epistemológicos da teoria de Fedathi no ensino de matemática. In: Encontro de Pesquisa Educacional do Norte e Nordeste. Anais. São Luís: UFMA, 2001

CHEVALLARD, Y. et al. Estudar Matemáticas: $O$ elo perdido entre o ensino e a aprendizagem. Porto Alegre: Artmed Editora, 2001

D’AMBROSIO, U. Educação Matemática: Da teoria à prática. Papirus Editora, 2012.

DAVIS, P. J; HERSH, R. A Experiência Matemática. Lisboa: Gradativa, 1995.

DEMO, Pedro. A Nova LDB: Ranços e Avanços. Papirus Editora, 2012.

DE SOUSA, F. E.; BORGES NETO, H. Sequência Fedathi: Os algarismos romanos revisitados na formação contínua de professores de matemática; Anais do XVI EPENN - Encontro de Pesquisa Educacional do Nordeste: Educação, Pesquisa e Diversidade Regional, vol. único, junho 2003, Aracajú (SE), p652. (CDD: 370.981)

FONTENELE, F. C. F. Maturação. In BORGES NETO, H. et al. Sequencia Fedathi: fundamentos. V. 3. Curitiba: CRV, 2018

LAKATOS, I. A lógica do descobrimento matemático: Provas e Refutações. Tradução de Nathanael C. Caixeiro, Rio de janeiro, Zahar Editores, 1978.

LORENZATO, S. Formação de Professores: Para aprender Matemática. Autores Associados, 2006.

MENDES, I, A. Matemática e investigação em sala de aula. Livraria da Física, 2009.

MENEZES et. al. A aplicação de problemas sobre taxas relacionadas com a metodologia Sequência Fedathi. Encontro Nacional de Educação Matemática. Anais. 2016.

POLYA, G. A Arte de resolver problemas. trad. Lisboa de Araújo, Rio de Janeiro, Interciência, 1978. 